\title{
Pannus Tissue Mimicking Enchondroma
}

TAYFUN AKALIN, MD, Kayseri Education and Research Hospital, Department of Internal Medicine, Kayseri; BERNA GOKER, MD, Gazi University, Department of Internal Medicine, Section of Rheumatology, Ankara; and HAKAN SELEK, MD, Gazi University, Department of Orthopaedic and Traumatology, Ankara, Turkey. Address correspondence to Dr. T. Akalin, Kayseri Education and Research Hospital, Department of Internal Medicine, Kayseri, Turkey. E-mail: tayfunakalin@yahoo.com. J Rheumatol 2014;41:352-3; doi:10.3899/jrheum.130846

It is unusual to find rheumatoid nodules in synovium ${ }^{1}$. We report a case of an invasion of medullary bone by pannus tissue associated with rheumatoid nodules.

A 46-year-old woman presented with a 4-year history of
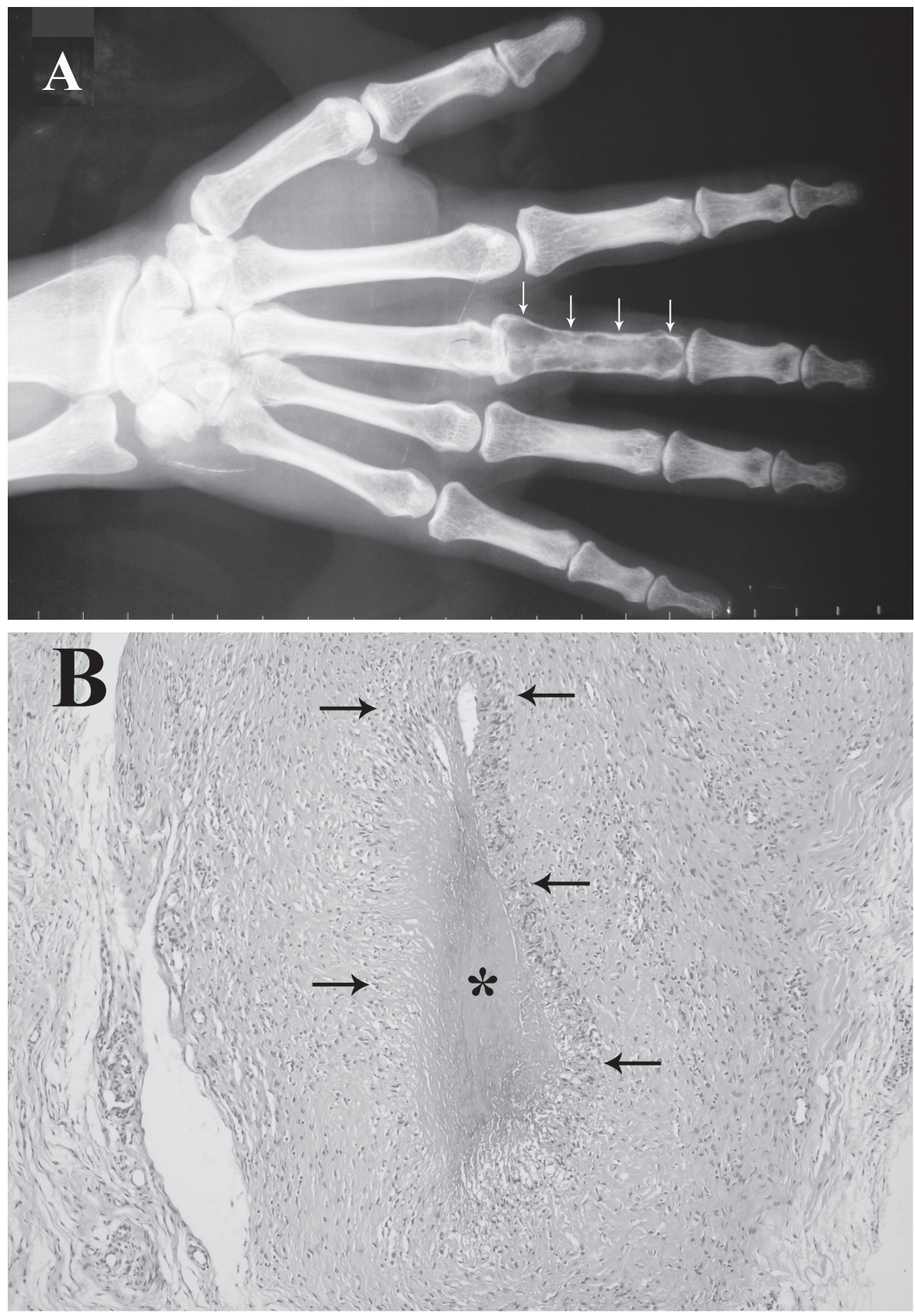

persistent pain in her left third metacarpophalangeal (MCP) joint. She was diagnosed with rheumatoid arthritis 13 years ago and was taking methotrexate and leflunomide treatments for 9 years. On admission, physical examination was

Figure 1. Pannus tissue mimicking enchondroma. (A) Cystic lesion occupying the entire third proximal phalanx (arrows). (B) Rheumatoid nodule in synovium with fibrinoid necrosis (asterisk) and palisading histiocytes (arrows). 
unremarkable except for mild tenderness in the third MCP joint. Plain radiographs of the left hand showed a cystic lesion occupying the entire third proximal phalanx (Figure 1A). Enchondroma was suspected. However, magnetic resonance imaging of the left hand revealed an intramedullary cystic lesion and pannus tissue in the third proximal phalanx. The pannus tissue eroded the cortical bone and invaded the medulla. Pericortical and intramedullary pannus tissues were excised. Pathologic examination of the biopsy specimen showed 3 rheumatoid nodules in the pannus tissue. Figure 1B shows 1 of the nodules with fibrinoid necrosis and palisading histiocytes.
Rheumatoid nodules in synovium are rare $^{1}$. To our knowledge, invasion of medullary bone by pannus tissue associated with rheumatoid nodules has not been reported previously. In our case, it led to misinterpretation of the lesion as enchondroma, a benign tumor of the cartilage mostly involving tubular bones of the hands.

\section{REFERENCE}

1. Diaz-Torne C, Schumacher HR, Einhorn E, Pessler F. Clinical Images: rheumatoid nodules in synovium. Arthritis Rheum 2007;56:2104. 